\title{
Experience of patients and practitioners with a team and technology approach to chronic back disorder management
}

This article was published in the following Dove Press journal:

Journal of Multidisciplinary Healthcare

\author{
Stacey Lovo' \\ L Harrison ' \\ ME O'Connell ${ }^{2}$ \\ C Trask ${ }^{3}$ \\ B Bath ${ }^{1,3}$
}

'School of Rehabilitation Science, University of Saskatchewan, Saskatoon, SK S7N 2Z4, Canada; ${ }^{2}$ College of Arts and Science, University of Saskatchewan, Saskatoon, SK S7N 5A5, Canada;

${ }^{3}$ Canadian Centre for Health and Safety in Agriculture, College of Medicine, University of Saskatchewan, Saskatoon, SK S7N 2Z4, Canada
Correspondence: Stacey Lovo School of Rehabilitation Science, University of Saskatchewan, Health Sciences Building, E-Wing Suite 3400, 3rd Floor, 104 Clinic Place, Saskatoon, SK S7N 2Z4, Canada

Tel + I 3062419545

Email stacey.lovo@usask.ca
Purpose: Although rural and remote residents face general challenges accessing health care in comparison to urban dwellers, care for musculoskeletal conditions like chronic back disorders (CBD) is particularly challenging for rural and remote residents due to lack of access to physical yherapists. Telerehabilitation such as secure videoconferencing offers one solution to this disparity in rural care delivery, but incorporating the perspectives of health practitioners and patients is important when developing new sustainable care models.

Patients and methods: This study investigated the experiences of practitioners and patients during a novel interprofessional model of assessment where an urban-based physical therapist used videoconferencing to virtually join a rural nurse practitioner and a rural patient with CBD. Patient surveys and semi-structured interviews of practitioners and patients were analyzed quantitatively and qualitatively.

Results: Most patients were "very satisfied" (62.1\%) or "satisfied" (31.6\%) with the overall experience, and "very" $(63.1 \%)$ or "somewhat (36.9\%) confident" with the assessment. Thematic analysis of interviews revealed that this novel assessment method identified: access to care for $\mathrm{CBD}$, effective interprofessional practice, enhanced clinical care for $\mathrm{CBD}$, and technology considerations.

Conclusion: Patient satisfaction with the telerehabilitation model of care was high. Patients and practitioners reported their experiences were impacted by access to care, interprofessional practice, enhanced care for CBD and technology. These findings will be useful in the development of patient-centered models of care utilizing telehealth strategies.

Keywords: telemedicine, interprofessional relations, low back pain, physical therapy, patient-centered care

\section{Introduction}

Rural and remote Canadians experience difficulties accessing health care that are not experienced by urban dwellers. ${ }^{1-3}$ Travel and weather can make health care access very difficult. ${ }^{1,2,4}$ In order for rural and remote patients to access care by physical therapists (PTs) who specialize in musculoskeletal care, it may be necessary to travel long distances since practitioners who specialize in these conditions are in particularly short supply in rural areas. ${ }^{5}$ Traveling long distances for care also means time lost from work and family activities.

Rural health care disparities can be seen within the broader health care access literature. Most notably, Thomas and Perchansky identified several important aspects of access to care: availability, accessibility, accommodation, affordability, 
and acceptability to the patient. ${ }^{6}$ In terms of availability, there are fewer health care professionals in rural than in urban areas. ${ }^{1,7}$ PTs are an example of a profession with reduced numbers in rural and remote regions. One-third of Saskatchewan residents live in rural areas, ${ }^{8}$ but only $10 \%$ of the PTs work in rural areas. ${ }^{5}$ This lack of rural access has particular implications for chronic musculoskeletal disorders. One study compared experienced PTs knowledge of musculoskeletal disorders to that of physicians and specialists, and found PTs had greater knowledge about musculoskeletal management than physicians, except orthopedic surgeons. ${ }^{9}$ This helps to underscore why the inclusion of PTs on primary care teams managing CBD is important.

Due, at least in part, to the lack of PTs in rural and remote areas, physicians and nurse practitioners (NPs) are primarily involved in management of CBD in rural and remote regions. NPs are primary health care providers who practice autonomously in clinics where physician numbers are reduced..$^{10}$ In Saskatchewan, 55\% of the NPs practice in rural locations, compared to $25 \%$ of the family physicians. ${ }^{11}$ Shah et al found that NPs may be improving primary health care access in some rural Saskatchewan areas, such as Kelsey Trail Health Region (the site of the present study). ${ }^{12}$ NPs provide the first portal of entry into the health care system for many patients. Following a physical exam and appropriate investigations, the NP facilitates a referral to the appropriate health professional. ${ }^{13}$

Rural and remote Canadians are 30\% more likely than urban dwellers to have CBD. ${ }^{14}$ Salemink refers to a rural paradox, which describes the situation in which rural areas that need enhanced digital access the most are the ones who have it the least. ${ }^{15}$ A rural paradox is also found in the diminished PT services available to rural Canadians who are more likely than urban people to have CBD. In a Canadian study, the majority of users $(64.7 \%)$ of an urban-based spinal assessment program led by PTs were from rural and remote areas, highlighting a potential need for more rural and remote CBD services. ${ }^{16}$ Notably, patients and rural referring primary care providers of the spine triage service identified limited PT availability as a barrier to managing $\mathrm{CBD}$ in their region. ${ }^{17}$ Briggs et al studied the experiences of rural Australians with back pain ${ }^{18}$ patients described limited resources and particularly limited CBD-specific care. Patients reported that rural health care teams lacked pain management experience and "integrate(d) care with other non-medical practitioners" for interdisciplinary management planning.
Innovative ways to bring PTs and other professionals to rural areas to join primary health care teams are needed to enhance care for CBD. Patients in Australia showed optimism about using telemedicine to improve availability of pain management professionals. ${ }^{18}$ Telehealth has been used for PT assessment of some components of spinal conditions, such as measurements of range of motion and straight leg raise. ${ }^{19,20}$ The obvious disadvantage to PT over telehealth is the inability of the PT to directly perform physical components of the assessment. To address this, Lovo Grona et al completed a lumbar neuromusculoskeletal assessment and management protocol for a CBD patient using remote presence robotics, ${ }^{21}$ in which an urban PT consultant joined an NP and patient in a remote northern area. This case study was the first known team and technology approach to management of CBD in the literature. The NP performed all physical components of the examination, with the PT consulting. Further investigation joining PTs with rural and remote care teams using telehealth strategies to improve options for rural patient care are needed.

Enhancing access to PT in rural and remote regions could be facilitated through a team and technology model of care, which capitalizes on complementary interprofessional skills sets, such as those of PTs and NPs. The Canadian Interprofessional Health Collaborative (CIHC) National Interprofessional Competency Framework defines interprofessional collaboration as "a partnership between a team of health providers and a client in a participatory, collaborative and coordinated approached to shared decision-making around health and social issues". ${ }^{22}$ PTs are primary practitioners with expertise in injury and functional recovery, pain management, and movement. NPs are primary practitioners with advanced scopes of practice including completing referrals to specialists, ordering diagnostic imaging, and prescription of medication. Both practitioners have expert knowledge and skills in patient assessment. Given their complementary skills a PT/NP team approach would appear ideal, but this approach would only be successful if it were responsive to the goals of both patients and practitioners. Goldman et al evaluated interprofessional practice protocols and discussed the importance of health professionals' opinions on development and acceptance of new models of care. ${ }^{23}$

Understanding the experiences of patients and practitioners is vital to designing effective service delivery strategies for new care models in rural and remote regions. In a systematic review, Kairy et al reported limited available 
evidence on patient experience with telerehabilitation. ${ }^{24}$ One study reported positive experiences among 5 patients who were cared for by a PT using telehealth, ${ }^{25}$ and a single case study reported on the experience of a patient and NP who utilized a team and technology approach. ${ }^{21}$ The present study will build on the case study by Lovo Grona et al, which examined the experience of one patient and one practitioner with a team and technology approach to care. ${ }^{21}$

The objective of this study was to describe the experience of health care providers and patients who participated in a team and technology model of care for management of CBD. This study will examine the experiences of the interprofessional team members and the patients who participated in the team and technology model of care for management of CBD.

\section{Materials and methods}

A randomized controlled trial (RCT) pilot study was conducted in a rural community $264 \mathrm{~km}$ drive from the research center. ${ }^{26} \mathrm{PT}$ was not available within the community, and patients who required PT needed to travel 30 mins to a regional center, after an approximate 6-month wait. Participants were recruited via posters, newspaper ads, social media, and through information provided at primary practitioner visits in the community. Inclusion criteria included ages $18-80$ years as well as the presence of low back and/or leg-related pain bad enough to limit usual activities and present for at least 3 months. Exclusion criteria included presence of third-party payer funding for the back problem, primarily neck or upper back pain, and language, reading or comprehension barriers that would prevent completion of the study paperwork. Sixty-four participants in the study were randomly assigned to one of three groups: 1) PT in person $(\mathrm{n}=20), 2)$ NP in person ( $\mathrm{n}=19$, usual care group), and 3 ) urban PT using telehealth to join NP and participant $(n=20$ $\left.\mathrm{PT} / \mathrm{NP}_{\text {team }}\right)$. Six participants withdrew the NP in person group prior to the beginning of the intervention due to withdrawal, no show or resolution of symptoms. Prior to onset of the study, as well as once during the study and after it was completed, the telehealth PT traveled by car to the rural community to meet with the NP in person. The group assigned to the $\mathrm{PT} / \mathrm{NP}_{\text {team }}$ approach is the only group of participants that will be described in this manuscript, and within the present study, they are not compared to the other groups in the RCT. Twenty patients participated in the $\mathrm{PT} / \mathrm{NP}_{\text {team }}$ using videoconferencing group. One patient withdrew mid-study leaving 19 patients. Only the experiences of the participants (patients and health professionals) in the $\mathrm{PT} / \mathrm{NP}_{\text {team }}$ group will be described.

The team used a laptop with VidyoDesktop Software Inc. (Vidyo Inc, Hackensack, NJ, USA). ${ }^{27}$ An external web camera with pan, tilt, and zoom functionalities was located at the NP and patient site; this device transmitted audio and video to the consultant urban PT. Figure 1 shows the viewpoint of the urban-based PT. A full neuromusculoskeletal assessment for the lumbar spine was completed on each patient. Patients were provided with a lay summary of assessment findings, management recommendations, and education regarding expectations for treatment needs, as well as answers to any questions they had.

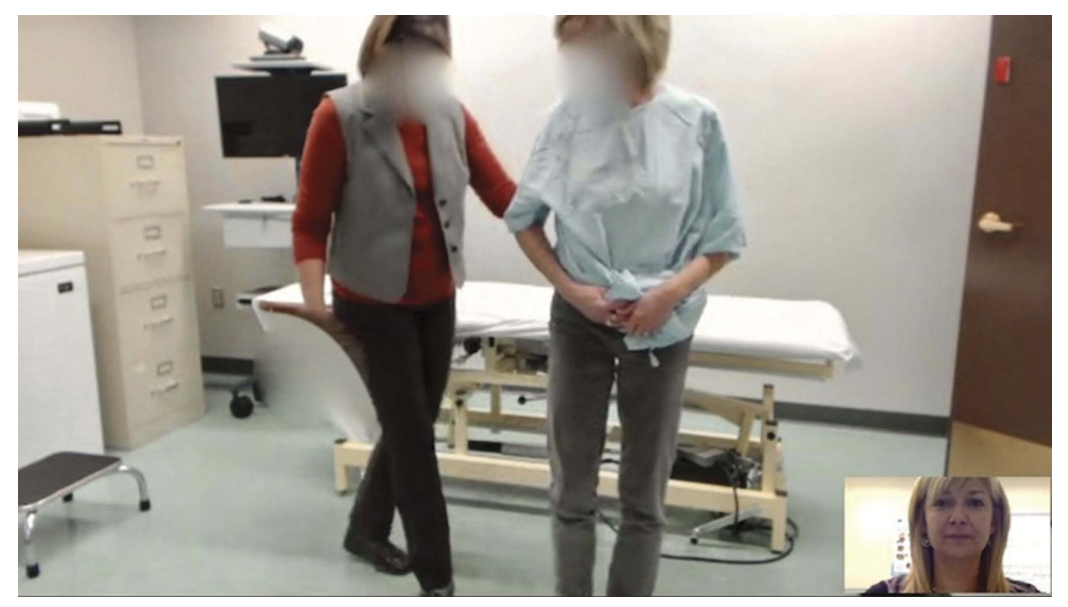

Figure I Physical therapist (shown in inset) view of nurse practitioner and model patient, using Vidyo secure web-based telehealth platform. ${ }^{27}$ The physical therapist has provided written informed consent for her photo to be included in this manuscript. 


\section{Data collection and data analysis}

The experience of patients in the telehealth group was measured by a modified version of a survey initially developed by Russell et al. ${ }^{28}$ The authors modified the original survey with a Likert scale, whereas the original scale was graded on a line. There were 5 descriptors in the Likert scale modified version. An additional modification was an open-ended question allowing participant comments. The modified survey is shown in Table 1 . Surveys were completed by patients in the $\mathrm{PT} / \mathrm{NP}_{\text {team }}$ group, $2-4$ weeks after the intervention. ${ }^{26}$ Proportions, medians, and interquartile ranges (IQR) were calculated for each survey item.

The 2 health practitioners (PT and NP) and 6 of the 19 participants involved in the $\mathrm{PT} / \mathrm{NP}_{\text {team }}$ arm of the $\mathrm{RCT}$ participated in a semi-structured interview by telephone, 2-4 weeks after the study period, about their experiences with the model of care. The interview guides for the participants and providers can be found in the Appendix. Two researchers conducted interviewers, one interviewing the practitioners and the other interviewing the patients. Interviewers were trained and experienced in performing semi-structured interviews.

Qualitative analysis involved an iterative thematic approach using open and axial coding for the open-ended patient experience survey question as well as the semistructured interviews of patients and practitioners. The analysis steps included: 1) data familiarization, 2) code generation, 3) identifying themes from codes, 4) review and naming of themes, and 5) choosing strong examples that demonstrate importance of themes to the research objectives and question. ${ }^{29,30}$ During open coding, categories of codes were created, and from there, overarching themes were generated. After open coding, axial coding involved examination of relationships between themes. ${ }^{28}$ Two researchers (SLG \& BB, both PTs) jointly developed the coding scheme and then verified categories and themes independently. A third (MEO, clinical psychologist) and fourth reviewer (EH, PT) examined the coding of themes through an interprofessional lens. A final reviewer (CT) reviewed themes with a non-health care professional lens.

Although there were no a priori categories, the team noted during theme review that the subthemes in one of the primary themes resembled an existing framework, the Canadian Interprofessional Health Collaborative (CIHC) National Interprofessional Competency Framework. $^{22}$ The subthemes were therefore developed in combination with a text driven-open coding method and the team's perceived alignment with the established definitions of the CIHC; some of the definitions from CIHC were used in part to describe the themes. In this way, the CIHC framework was used to help categorize some of the subthemes. It was also noted by the team that some quotes fit more than one theme. Through discussion, the reviewers refined themes and came to a final consensus. The NP reviewed the final draft manuscript as a form of member checking and agreed with the presentation of themes in the analysis.

\section{Ethical considerations}

All participants provided written consent for participation in this study. This study was approved by the University of Saskatchewan Biomedical Ethics Board (12-341).

\section{Results}

Patient demographics for the telehealth experience survey $(n=19)$ are shown in Table 2. Patients were "very satisfied" $(62.1 \%)$ or "satisfied" $(31.6 \%)$ with the overall experience and "very confident" (63.1\%) or "somewhat confident" $(36.9 \%)$ with the assessment. As high as $78.9 \%$ indicated that they "would recommend" telehealth to others. As high as $42.1 \%$ found telehealth "comparable" to face to face, $36.8 \%$ found it "somewhat comparable", $15.8 \%$ were neutral, and 5.3\% said it was "not likely comparable". Both audio and visual quality were rated highly, with only $5.3 \%$ rating this as "not sure" or "not really clear". Complete results from the telehealth experience survey questions are presented in Table 3 .

Two health care providers (PT and NP) and six patients participated in semi-structured interviews following the intervention. Both health care providers were female, with 22 and 26 years of experience, respectively, for the PT and the NP. Four primary themes were identified: 1) access to care for $\mathrm{CBD}, 2$ ) effective interprofessional practice, 3) enhanced clinical care for CBD, and 4) technology.

Figure 2 describes the relationship of the primary themes, including the area of overlap between teams (effective interprofessional practice), technology and enhanced clinical care for $\mathrm{CBD}$, which is access to care for $\mathrm{CBD}$.

\section{Access to care for $C B D$}

Access to care for $\mathrm{CBD}$ was defined as the ability to achieve appropriate PT care in the patient's own rural community for a chronic condition of the lumbar spine. Access to care for CBD had three sub-themes: less travel; 


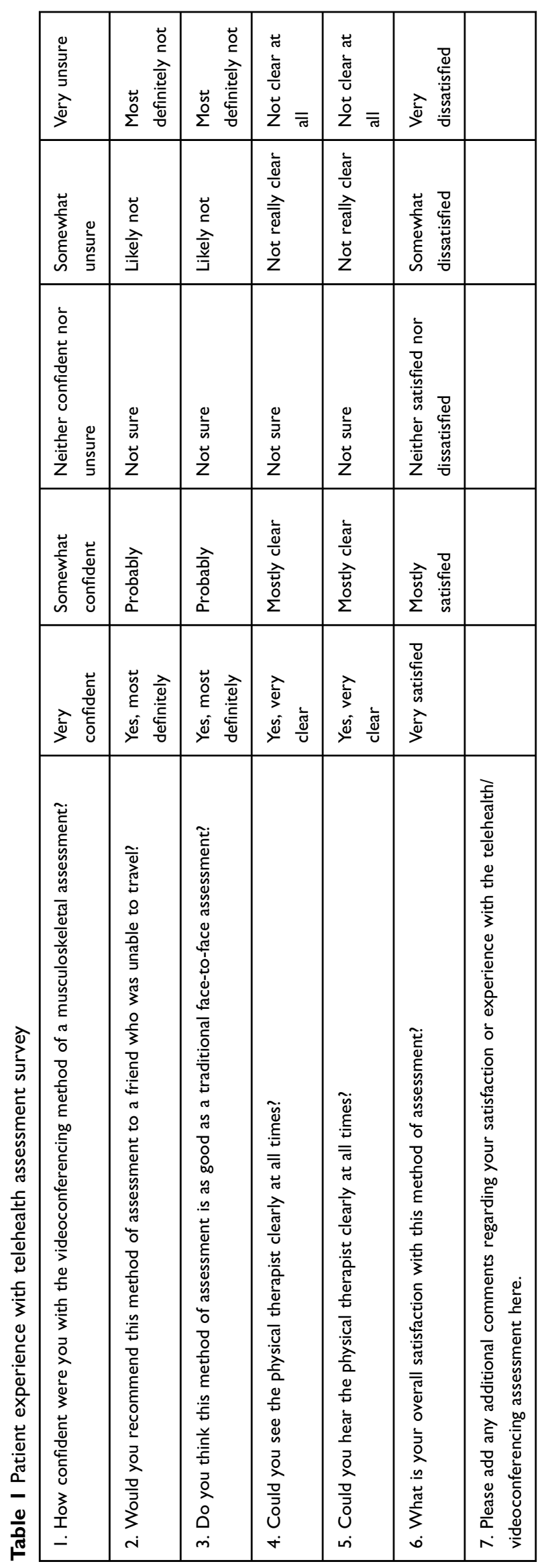


Table 2 Patient demographics $(n=19)$ : CBD patients participating in a team and technology approach to care

\begin{tabular}{|l|l|l|}
\hline Variable & $\begin{array}{l}\text { Participant } \\
\text { demographics }\end{array}$ & Proportion \\
\hline Age (mean, SD) & $50.84,13.87$ & \\
\hline BMI classification & $\mathbf{n}$ & $\%$ \\
Normal & 4 & 21.1 \\
Overweight & 7 & 36.8 \\
Obesity & 8 & 42.1 \\
\hline Gender & & \\
Female & 11 & 57.9 \\
Male & 8 & 42.1 \\
\hline Marital status & & \\
Married & 14 & 73.7 \\
Divorced/widowed/ & 5 & 26.3 \\
never married & & \\
\hline
\end{tabular}

more convenient; community-based care; and enhanced access to physical therapy care.

a) Less travel, more convenient:

The subtheme of less travel, more convenient refers to being able to have care provided locally, without driving to an urban center. The NP identified convenience in the team and technology model, specifically indicating "they don't have to take a day off work and drive to surrounding communities or Saskatoon". Patients reported time saved with less driving and noted the benefit to the elderly who would not have to drive.

b) Community-based care:

The theme of community-based care relates to care provided in the context of rural living, fitting for the rural people's lifestyles, and involving known and trusted practitioners. The PT reported: "the appreciation of the service being offered locally was much greater than I had anticipated". Patients were familiar with and trusted the NP, and this existing relationship led to increased confidence with the new model of care evidenced in this patient statement: "if I saw [the NP] on a regular basis then she's kind of fully aware of what issues are going on and then they can work together to figure out a plan or whatever for me". Another patient noted "if we can bring this here and use the resources in this area, then why not" which emphasizes the importance of optimizing use of health care space and human resources already available, as well as building capacity within rural communities. Financial and functional ability/disability needs may be unique to rural communities as well, due to the increased costs to travel for out-of-town care. For example, the NP stated "if I have a patient that's not terribly mobile or financially is a little strapped, it allows them a really great assessment and not have to leave the community".

c) Enhanced access to PT care:

The subtheme of enhanced access to PT care referred to available and timely care by a PT. The rural NP noted that there was a delay in care in their community due to a "significant challenge with [the local rural] PT department keeping up with the community needs". The PT on the telehealth team reported "I can get the great majority of the information I need to help them over videoconferencing and I think it would make our in-person visits more efficient and usable". The ability for the PT to join via telehealth made it possible for PT services to be provided where they otherwise would not be. One of the patients reported: "if this works and this is something we can do, I think that would speed up some of the process (for accessing appropriate care)".

\section{Effective interprofessional practice (the team)}

Effective interprofessional practice and its subthemes were defined using input from the CIHC definitions. Effective interprofessional practice was defined as "the process of

Table 3 Patient-reported experiences with telehealth assessment $(n=19)$

\begin{tabular}{|l|l|l|l|l|l|}
\hline Question & $\begin{array}{l}\text { Very or yes, } \\
\text { n (\%) }\end{array}$ & $\begin{array}{l}\text { Somewhat or } \\
\text { probably, } \\
\text { n (\%) }\end{array}$ & $\begin{array}{l}\text { Neutral, } \\
\text { n (\%) }\end{array}$ & $\begin{array}{l}\text { Somewhat unsure or } \\
\text { not likely, } \\
\text { n (\%) }\end{array}$ & $\begin{array}{l}\text { Very unsure or not } \\
\text { at all, } \\
\text { n (\%) }\end{array}$ \\
\hline Confidence with assessment & $12 / 19(63.1)$ & $7 / 19(36.9)$ & 0 & 0 & 0 \\
Recommendation to others & $15 / 19(78.9)$ & $4 / 19(21.1)$ & 0 & 0 & 0 \\
Comparison to face to face & $8 / 19(42.1)$ & $7 / 19(36.8)$ & $3 / 19(15.8)$ & $1 / 19(5.3)$ & 0 \\
Visual clarity & $15 / 19(78.9)$ & $3 / 19(15.8)$ & 0 & $1 / 19(5.3)$ & 0 \\
Audio clarity & $13 / 19(68.4)$ & $5 / 19(26.3)$ & 0 & $1 / 19(5.3)$ & 0 \\
Overall satisfaction & $13 / 19(68.4)$ & $6 / 19(31.6)$ & 0 & 0 & 0 \\
\hline
\end{tabular}




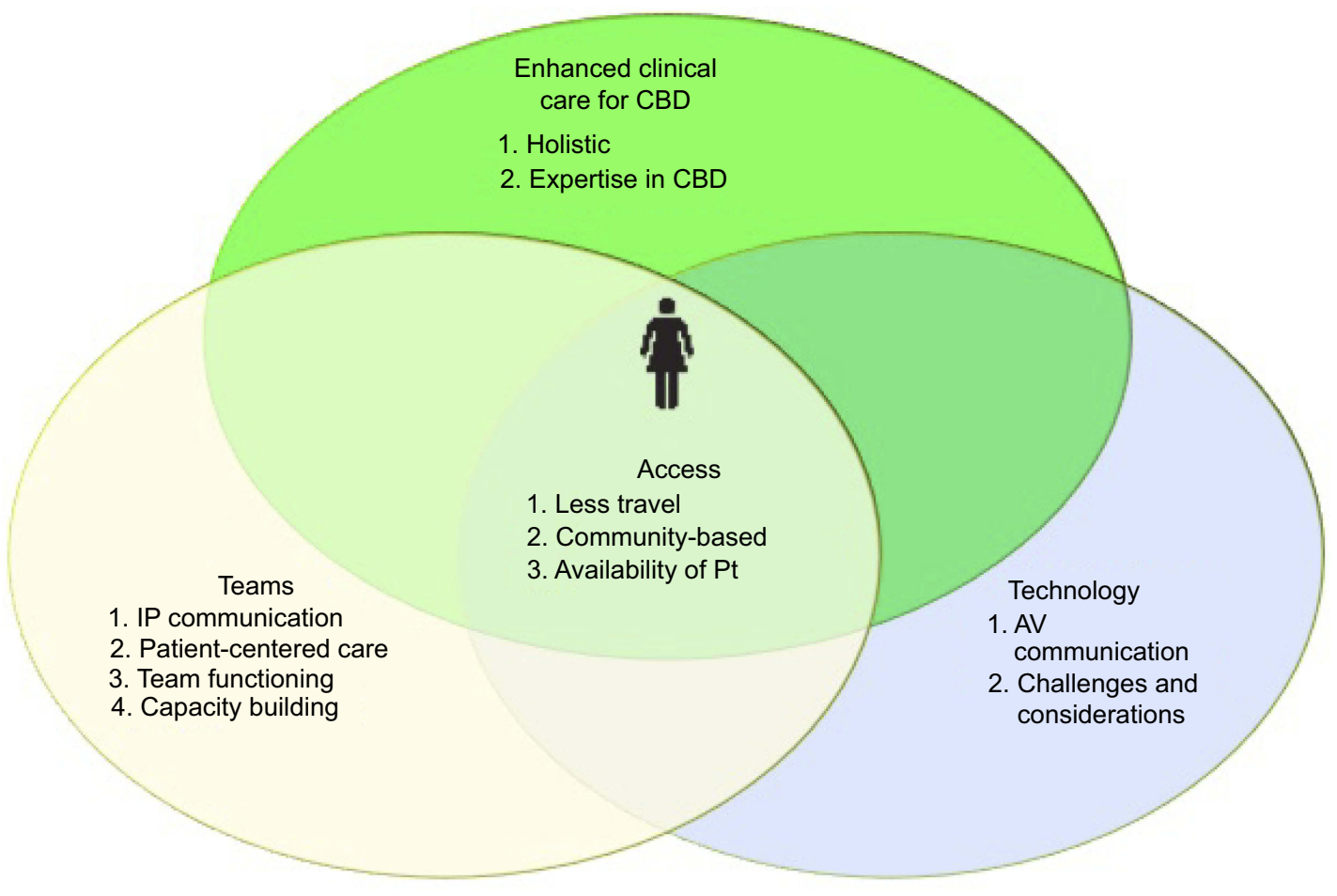

Figure 2 Model describing the relationship between themes as described by participants in a team and technology model of CBD care.

developing and maintaining effective interprofessional working relationships to enable optimal health outcomes". 22 The broad theme of interprofessional practice was divided into four subthemes: interprofessional communication, patient-centered care, team functioning, and capacity building.

a) Interprofessional communication:

Interprofessional communication referred to communication within the team including mutual understanding and trust. ${ }^{22}$ The goal of interprofessional communication should be to improve the quality of care. The PT suggested that the relationship with the NP developed throughout the research process and was an important factor in successful communication: "it may be more challenging if the two team members were strangers to each other or had never met or talked repeatedly by videoconferencing". This was interpreted as meaning trust and rapport had developed throughout the intervention period, as it would with any team as the team members spend more time together. Patients noted the practitioners "could communicate back and forth and with me at the same time instead of having to go to the one and then a week later going to the other one" and that it was like "two pairs of professional hands in one room." This appears to indicate that the patient saw the practitioners as a functioning unit. b) Patient-centered care:

For the purposes of this study, we defined patientcentered care as patient involvement and engagement, including sufficient patient education and listening to patient needs. ${ }^{22}$ Patient-centered care will meet a patient's goals and will be of high quality. The NP summarized how well this interprofessional assessment using telehealth met the needs/goals of the patient and provided patient-centered care:

I think that when a patient has a number of different practitioners working together to move them forward along the continuum of wellness I think that ... it's going to ensure that everybody is on the same page.

And "we expanded the patients' treatment options in that one visit by using the two [practitioners]". She explained what happens with patients who suffer from CBD without the interprofessional telehealth approach, receiving care that is instead not centered around their needs: "right now I see our patients are being sent all over the place and they're not necessarily receiving the appropriate treatment. There's a great deal expense and time and poor outcomes". Both the description of the team cohesion and the ability to receive focused care at one time describe the patient-centered care provided in this model. One 
patient commented on her impression of the end result and spoke to the potential quality of care available through a team and technology model: "as far as I was concerned, as accurately diagnosed and as thoroughly diagnosed as I've ever been for my back. And it took 45 mins. They didn't rush. They did a full, proper assessment."

c) Team functioning:

The subtheme of team functioning referred to effective teamwork and processes, including respectful interactions and relationships, as defined by $\mathrm{CIHC} .^{22}$ In this case, the team functioning occurred through the unique use of technology. The PT stated: "I felt that I was providing expertise that was not available without me so I felt that my role on the interprofessional team was very relevant". The NP provided a unique perspective on what it felt like to function on the telehealth team, saying she "was sort of an extension of the PTs arm". Patients reported an appreciation for the team aspect of the model of care: "I felt better just knowing I didn't have just one professional". The traditional method of care in that area would be for the patient to see an NP by herself, in-person. A team was created and present in this case due to the team and technology model of care. The ability of the team to function as a result of telehealth technology was clear for this patient: "they can't physically be here, but their skills are just as effective on that screen if they have a trained pair of hands to use".

\section{d) Capacity building:}

Capacity building was defined using the World Health Organization (WHO) definition: "human resources, institutional and infrastructural capacity, and networks and partnerships". ${ }^{31}$ In this case, capacity for human resources and local, rural systems was being enhanced by this model of perhaps a result of professionals being aware of the needs of various patient populations: "I think we could enhance the way that we manage pain, especially in elderly people or most urgently in elderly people by having a team approach" (PT). The NP identified additional professions that could enhance the team: "pharmacists have a lot of input that they can offer us when we're trying to do the best type of medication reconciliation and pain management for our patients" and the PT noted that in two cases, she consulted other professionals by phone:

It would have been helpful if the PT and exercise therapist could have communicated via videoconferencing. In another case, I engaged an academic scholar in a specialty area to provide information to the exercise therapist.
The ability to join professionals with rural teams using telehealth could mean limitless potential for community healthcare capacity building.

\section{Enhanced clinical care for CBD}

Enhanced clinical care for CBD relates to the availability of care compared to what was previously available to patients in that region. It had two subthemes: holistic care and expertise in CBD.

a) Holistic care:

Holistic care referred to recognition of the whole person's needs. The practitioners noted an expanded availability of services within the appointments, saying "they were able to address all of their assessment and management planning needs", and to "provide [medication] prescriptions and consult for specialist care" when needed. A patient concurred, describing the comprehensive nature of their assessment: "a full assessment of [their] back, x-rays done, blood work, and suggestions for what [they] could do". In uniprofessional care, all of these different treatments would not typically be provided in one primary care visit (eg, education about CBD, diagnostics, and blood tests). Multiple visits to different practitioners would be required to have all of these needs met in usual primary care (non-team based) scenario.

b) Expertise in CBD:

This subtheme referred to the presence of specific expertise and experience in CBD management where this was not previously available. The PT indicated that a full neuromusculoskeletal screening and management approach had not previously been the norm for the participants of the study: "the majority of people had not been through a conservative-care approach to their back pain". The NP reported a change in practice style as a result of the model of care: "when I do an assessment of someone that comes into my clinic that is experiencing back pain, my assessments are a little bit more systematic because of course I'm comfortable doing this now." Patient statements concurred with the practitioners' impressions that comprehensive care was provided with the team and technology model: "I got more feedback from [the assessment] than I did just going to my doctor's" as well as "I've had numerous things done and still have it [back pain] ... so I'm kind of excited that I've noticed a bit of difference in my back already."

\section{Technology}

$\mathrm{COACH}$ (2015) described telehealth as joining patients with health care professionals using video, audio, and 
health information. ${ }^{32}$ In the context of the team and technology care model, technology is operationally defined as per the COACH definition of telehealth. ${ }^{32}$ In this case, the technology utilized in the intervention was a traditional laptop telehealth system. Technology was divided into two subthemes: audiovisual communication and other challenges and considerations.

a) Audiovisual communication:

This subtheme described the contribution of audio and visual mechanical components to quality of the interaction between the team members and the patient. The PT reported

we had a camera that was clear, easy to use, and quite valuable when it came to fine details. On two occasions we lost the camera and the laptop-based camera wasn't as clear or didn't show as intricate of details so the quality of the camera was a big factor.

The PT also noted the importance of backup planning: "we did need to add external mini speakers to improve the audio when we lost our main camera." The NP reported

we had some glitches with our electronics. I think we have to look at that and maybe better accommodate our patients because I know our volume was a challenge for some of our people that had a bit of a hearing deficit. And it is a smaller screen size so for people that want to see (the PT)

I'm working with- I think that needs to be addressed too.

Patients reported experiencing no difficulties with communication due to technology, and accepted its use: "I like to embrace technology. It's here to stay and there's a lot of benefits to it ... let's use it when we can".

b) Other challenges and considerations:

This subtheme explained areas other than audiovisual components to consider about technology when developing clinical protocols or undertaking future research. The NP reported that the office assistant's comfort level with technology was an important factor in facilitating efficient patient flow: "our office manager really has kept this flowing very smoothly for me. Thank goodness because I might not be nearly as excited about this if she hadn't been able to make it work". One potential challenge with technology that was expressed by patients was "the older people might not like it".

\section{Discussion}

This study examined the experience of patients and health practitioners with an interprofessional model of CBD assessment using telehealth, a team and technology model of care for CBD. Patient participants were very or somewhat satisfied with the clinical experience overall and satisfied with their assessment. All reported they would, or probably would, recommend this format of assessment to others. While 79\% (15 out of 19) reported that the videoconferencing assessment was either comparable or probably comparable to a face-to-face assessment, it is notable that one patient participant reported that it was not comparable. The 19-person sample is small and therefore should not be considered an exhaustive normative or representative statement on acceptability to the whole population, but as a proof-of-concept. The generally positive findings suggest this model is a promising avenue to pursue in future research and consider in clinical practice.

Qualitative analysis of patient and practitioner interviews identified the following four main themes: access to care for CBD, efficient interprofessional practice, enhanced clinical care for CBD, and technology considerations. Practitioners and patients reported similar experiences, with the exception of the subtheme of capacity building, which due to their experience, would be something the practitioners would look for in a new model of care but that patients may not be aware of during their interaction. The relationship between the four themes is important: teams, technology, and enhanced clinical care for $C B D$ meet together to improve access to care for CBD for the rural patient. Patients and practitioners in this sample agreed that this model of care can provide improved access to care for CBD.

Access to care was also a theme identified in the qualitative study by Kairy et al on the use of telehealth for PT access. ${ }^{24}$ In the present study, diminished travel and the ability to have care delivered in their own community was appreciated by patients and the local NP, who also reported that access within their own community would enhance patients' willingness to seek care or to follow through with care plans.

Briggs et al interviewed patients who identified the use of telehealth to facilitate access to professionals who could provide expert care and pain management strategies for CBD in rural Australia. ${ }^{18}$ The present study is the first we are aware of that confirms that a team and technology approach to uniting experts in CBD management with a rural primary care team is met with overall satisfaction and acceptability from participants and health providers. The health providers in the present study described the mutual professional benefit, in terms of capacity building on the 
rural team, as well as enhanced practice due to the interprofessional team. This was also identified by practitioners who utilized remote presence robotics (another form of telehealth) to address a CBD case in remote northern Canada. $^{21}$

Effective interprofessional practice was a primary theme identified in our study. The present study builds on the $\mathrm{N}$ of 1 study by Lovo Grona et $\mathrm{al}^{21}$ with a larger sample, different technology, and a different rural community location. The CIHC identified

six competency domains of interprofessional practice: interprofessional communication, patient/client/family/ community-centered care, role clarification, team functioning, collaborative leadership and interprofessional conflict resolution. $^{22}$

The four subthemes under our primary theme of effective interprofessional practice included: interprofessional communication, patient-centered care, team functioning, and capacity building. Although the interview and initial coding process did not specifically target these concepts, three of our subthemes aligned closely with the CIHC competency domains. Two of the main descriptors of patientcentered care within CIHC's guidelines are "providing thorough education" and "respectful listening". ${ }^{22}$ Patient participants in this study described these aspects as being part of their experiences with the team and technology approach to CBD care. Trust is an important concept in interprofessional communication and team functioning and was considered in the design of the present study. The PT traveled to the community prior to, during and after the intervention to spend time with the local health care team. The team provided care to a number of patients and had time to develop a relationship. These factors likely made trust and interprofessional communication easier. Trust and team building have been previously shown to be important to patient outcomes ${ }^{22,33}$ and should be a part of any future team and technology applications.

Technology challenges and considerations have been identified previously in telehealth literature. Similar to the findings of Kairy et al in their study of home telerehabilitation, ${ }^{25}$ there were no major technology barriers in the present study that affected participant experience, although minor issues may have occurred during the process. The NP was located in the room with patients in our study, which likely provided enhanced confidence for patients than if they were alone with the urban-based health care provider during the intervention. In many cases, the NP had a history of rapport with these patients. The NP noted the importance of availability of an additional person who is able to facilitate the technology in order to ensure the NP's busy practice was not adversely affected. Although elderly rural residents were not specifically targeted in the study, participants thought that rural older adults may not be as interested due to technology requirements, which supports the findings by Sanders et al. ${ }^{34}$ It is notable, however, that other participants in the present study thought technology would be helpful in diminishing travel requirements for older rural residents. Lee and Coughlin (2015) noted perceived usefulness and potential benefit, knowledge of existence and availability, and perceived costs as 3 of the 10 facilitators which enhance the uptake of technology in older adults. ${ }^{35}$ The patients who experienced the team and technology model of care in the present study identified all three of these facilitators.

\section{Discussion of limitations}

According to Trainor $^{36}$ touchstones of qualitative interview research include: 1) sufficient sample to address research questions, 2) the interviewees have adequate experience, 3) researchers have established relationships with the study participants, 4) researchers acknowledge their position with respect to the work, 5) research questions and interview questions are clearly related, 6) methodology is clearly described, 7) analysis is clearly explained, 8) new information results from the interview research. In the case of the present study, the sample size of 6 patient interviews and 2 practitioner interviews provided the identified themes. All of the health practitioners in the study were sampled. Since there were not any others, this is a practical limitation of the study. There were only 2 practitioners, who had performed $20 \mathrm{CBD}$ assessments together, and their experiences would not necessarily be generalizable to other PT/NP teams or teams who had no experience working together. If we interviewed a larger sample of participants or patients, it is possible that new themes and subthemes could have emerged. Researchers identified themselves and their roles as practitioners (PT) and note that their physical therapists' lens may have contributed to interpretation of quotes and themes. Interview questions were designed to flesh out aspects of patient experience, and open-ended questions were provided to ensure interviewees had the ability to provide additional information. The authors note that the interviewer for the practitioners was not the same 
as the interviewer for patients. Although they followed a guide, there may have been differences in their style of questioning. Methods and analysis have been described to ensure transparency of the processes. Finally, the results provide novel information about the experience of a team and their patients in a team and technology model of care for CBD within a small study sample.

Morse (2015) also identifies touchstones for evaluating rigor in qualitative studies. ${ }^{37}$ The following were applicable to the present study: 1) Coding applied by the first 2 researchers was consistent and consensus was achieved at each stage of analysis. 2) Peer review was conducted with 3 additional interprofessional researchers. 3) Member checking was completed by the health professional interviewees after themes were identified and at completion of analysis.

This study has additional limitations to consider. The experience with telehealth survey (quantitative) had a small sample with only 19 participants which makes generalization to larger samples difficult. There is the likelihood of overly positive appraisals of the clinical service provided by patients, which is a common problem with patient satisfaction surveys. ${ }^{38}$ This model of care was implemented in the context of a funded research study. As such, the researchers had time for technical set up, brainstorming and problem solving if technical issues arose. This may not be the case in direct patient care settings with busy patient caseloads. In order to be successful, future implementation of similar models of care would need to have adequate resources for technology support and for building trust and team rapport.

\section{Conclusion}

The objective of this study was to examine the experiences of patients and practitioners who were involved in a team and technology model of care for the management of CBD. In this study, an urban-based consultant PT joined with a rural NP; the combination of their expertise ensured a trusted and skilled environment that facilitated successful interventions for rural CBD patients. The health practitioners provided enhanced clinical care for CBD through development of interprofessional (team-based) competencies and the use of telehealth technology. This resulted in improved access to care for rural patients with CBD. They did not have to travel to receive expert advice for their back pain, and their care was provided to them in their own community, alongside a local primary care provider.
This is a model that could be potentially adapted and implemented in other rural or remote areas. The next step would be to include other care providers who could contribute to holistic CBD management. Examples of other care providers who could participate in a CBD team include family physicians, medical specialists (ie, orthopedic or neurosurgeons, rheumatologists), pharmacists, and psychologists. Future research needs also include the evaluation of this model of care with other health conditions and evaluating the impact on short- and long-term health outcomes.

\section{Abbreviations}

CBD, chronic back disorder; PT, physical therapist; NP, nurse practitioner; RCT, randomized controlled trial; CIHC, Canadian interprofessional health collaborative.

\section{Acknowledgments}

The authors would like to thank E-health Saskatchewan for facilitating our use of the Vidyo Telehealth system used in this project, as well as to acknowledge Bourassa and Associates Rehabilitation Centre for the spinal triage service and electronic database utilized in this study. We would like to thank the Canadian Centre for Health and Safety in Agriculture for the clinical research space that was made available to us. We would like to thank Kelsey Trail Health region managers, health care practitioners, and staff who were essential to this project. We would also like to thank Research Assistant Blanc Star.

\section{Disclosure}

SLG received a Public Health in Agriculture and the Rural Ecosystem Fellowship and a Health Research Foundation of Canada Graduate Scholarship for her PhD work. BB and MEO received grants to support this research from the Saskatchewan Health Research Foundation, which did not have a specific role in the research. BB received a grant from the Kelsey Trail Health Region to support equipment purchase and operational expenses for the research andnon-financial support from eHealth Saskatchewan. BB also received funding to support travel to the national meeting from Saskatchewan Physiotherapy Association and Saskatchewan Health Research Foundation, grants from the College of Medicine, University of Saskatchewan and from Saskatchewan Centre for Patient Orientated Research, and a research contract from Canadian Association of Optometrists and from WorkSafe BC, outside the submitted work. The authors report no other conflicts of interest in this work. 


\section{References}

1. DesMeules M, Pong R, Lagace C, et al. How healthy are rural Canadians? An assessment of their health status and health determinants. Community Health (Bristol). 2006;1-182.

2. Kulig JC, Williams AM, editors. Health in Rural Canada. UBC Press; 2012.

3. Mikkonen J, Raphael D. Social Determinants of Health: The Canadian Facts [Internet]. Toronto: York University School of Public Health Management; 2010:62. Available from:. http://www. thecanadianfacts.org. Accessed August 5, 2019.

4. Andersson G. Epidemiological features of chronic low-back pain. Lancet. 1999;354(9178):581-585. doi:10.1016/S0140-6736(99)01312-4

5. Bath B, Gabrush G, Fritzler R, et al. Mapping the physiotherapy profession in Saskatchewan: examining rural versus urban practice patterns. Physioth Can. 2015;67(3):221-231. doi:10.3138/ptc.2014-53

6. Thomas J, Perchansky R. Relating satisfaction with access to utilization of services. Med Care. 1984;22(6):553-568. doi:10.1097/ 00005650-198406000-00006

7. PHAC. Understanding issues rural families face living in rural and remote communities [Internet]. The Rural Think Tank 2005. 2005. [cited March 1, 2014]. Available from: http://www.phac-aspc.gc.ca/ cphorsphc-respcacsp/2010/fr-rc/cphorsphc-respcacsp-06-eng.php. Accessed August 5, 2019.

8. Dandy K, Bollman RD. Seniors in rural Canada (Rural and Small Town Canada Bulletin Analysis, Vol. 7 Rural Small Town Anal Bull. 2008.

9. Childs JD, Whitman JM, Sizer PS, Pugia ML, Flynn TW, Delitto A A description of physical therapists' knowledge in managing musculoskeletal conditions. BMC Musculoskelet Di [Internet]. 2005;6:32. doi:10.1186/1471-2474-6-32

10. DiCenso A, Bourgeault I, Abelson J, et al. Utilization of nurse practitioners to increase patient access to primary healthcare in Canada-thinking outside the box. Nurs Leadersh. 2010;23:239-259. doi: $10.12927 / \mathrm{cjnl} .2010 .22281$

11. Canadian Institute for Health Information. Health workforce. Health Workforce Database. 2015 [cited August 18, 2017 ]. Available from: https://www.cihi.ca/en/health-workforce. Accessed August 5, 2019.

12. Shah TI, Milosavljevic S, Bath B. Determining geographic accessibility of family physician and nurse practitioner services in relation to the distribution of seniors within two Canadian Prairie Provinces. Soc Sci Med. Elsevier Ltd. 2017;194:96-104. doi:10.1016/j.socscimed.2017.10.019

13. Kowal L. Personal Communication. Arborfield (Saskatchewan); February 8, 2018.

14. Bath B, Trask C, McCrosky J, Lawson J. A biopsychosocial profile of adult Canadians with and without chronic back disorders: a population-based analysis of the 2009-2010 Canadian Community Health Surveys. Biomed Res Int. 2014;1-11. doi:10.1155/2014/919621

15. Salemink K, Strijker D, Bosworth G. Rural development in the digital age: A systematic literature review on unequal ICT availability, adoption, and use in rural areas. J Rural Stud. 2017;54:360-371. doi:10.1016/j.jrurstud.2015.09.001

16. Bath B, Grona SL, Janzen B. A spinal triage programme delivered by physiotherapists in collaboration with orthopaedic surgeons. Physiother Can. 2012;64(4):356-366. doi:10.3138/ptc.2011-29

17. Bath. B, Janzen B. Patient and referring health care provider satisfaction with a physitherapy spinal triage assessmetn service. $J$ Multidiscip Healthc. 2011;5:1-15. doi:10.2147/JMDH.S26375

18. Briggs AM, Slater H, Bunzli S, et al. Consumers' experiences of back pain in rural Western Australia: access to information and services, and self-management behaviours. BMC Health Serv Res [Internet]. 2012;12(1):357. Available from: http://www.pubmedcen tral.nih.gov/articlerender.fcgi? artid $=3494578 \&$ tool $=$ pmcentrez\&ren dertype $=$ abstract. Accessed August 5, 2019.
19. Truter P, Russell T, Fary R. The validity of physical therapy assessment of low back pain via telerehabilitation in a clinical setting. Telemed J E Health [Internet]. 2014;20(2):161-167. doi:10.1089/ tmj.2013.0088

20. Palacín-Marín F, Esteban-Moreno B, Olea N, Herrera-Viedma E, Arroyo-Morales M. Agreement between telerehabilitation and faceto-face clinical outcome assessments for low back pain in primary care. Spine [Internet]. 2013;38(11):947-952. doi:10.1097/ BRS.0b013e318281a36c

21. Grona SL, Bath B, Bustamante L, Mendez I. Case report: using a remote presence robot to improve access to physical therapy for people with chronic back disorders in an underserved community. Physiother Can. 2017;69(1):14-19. doi:10.3138/ptc.2015-77

22. CIHC. A National Interprofessional Competency Framework. University of British Columbia:. Vancouver; 2010.

23. Goldman J, Meuser J, Lawrie L, Roger J, Reeves S. Interprofessional primary care protocols: A strategy to promote an evidence-based approach to teamwork and the delivery of care. $J$ Interprof Care. 2010;24(6):653-665. doi:10.3109/13561820903550697

24. Kairy D, Lehoux P, Vincent C, Visintin M. A systematic review of clinical outcomes, clinical process, healthcare utilization and costs associated with telerehabilitation. Disabil Rehabil. 2009;31(6):427447. doi:10.1080/09638280802062553

25. Kairy D, Tousignant M, Leclerc N, Cote A-M, Levasseur M, Researchers T. The Patient's Perspective of in-Home Telerehabilitation Physiotherapy Services Following Total knee Arthroplasty. Int J Environ Res Public Heal 2013;10:3998-4011.

26. Bath B, Lovo Grona S, Milosavljevic S, Sari N, Imeah B, O’Connell M. Advancing interprofessional primary health care services in rural settings for people with chronic low back disorders: protocol of a community-based randomized controlled trial. J Med Internet Res [Internet]. 2016;5(4). Available from http://www.researchprotocols. org/2016/4/e212/. Accessed August 5, 2019.

27. VIDYO [software]. New Jersey: Vidyo, Inc. Available from: https:// www.vidyo.com/. Accessed January 1, 2014.

28. Russell T, Truter P, Blumke R, Richardson B. The diagnostic accuracy of telerehabilitation for nonarticular lower-limb musculoskeletal disorders. Telemedicine J E Health [Internet]. 2010;16(5):585-594. doi: $10.1089 / \mathrm{tmj} .2009 .0163$

29. Vaismoradi M, Turunen H, Bondas T. Content analysis and thematic analysis: Implications for conducting a qualitative descriptive study. Nurs Heal Sci. 2013;15(3):398-405. doi:10.1111/ nhs. 12048

30. Braun V, Clarke V. Using thematic analysis in psychology. Qual Res Psych. 2006;3:77-101. doi:10.1191/1478088706qp063oa

31. World Health Organization. Capacity building [Internet]. WHO Violence and Injury Prevention [cited December 10, 2017]. Available from: www.who.int/violence_injury_prevention/capacity building/en/.2018. Accessed August 5, 2019.

32. COACH. Canadian Telehalth Report. Canadian Telehealth Informatics Association. Toronto; 2015.

33. Wood V, Flavell A, Vanstoke D, Bainbridge L, Nasmith L. The road to collaboration: developing an interprofessional competency framework. J Interprof Care. 2009;23(6):621-629. doi:10.3109/ 13561820903051477

34. Sanders C, Rogers A, Bowen R, et al. Exploring barriers to participation and adoption of telehealth and telecare within the Whole System Demonstrator trial: a qualitative study. BMC Health Serv Res. 2012;12:220. Available from: https://bmchealthservres.biomedcen tral.com/articles/10.1186/1472-6963-12-220

35. Lee C, Coughlin J. Older adults' adoption of technology: an integrated approach to identifying determinants and barriers. J Prod Innov Manag. 2015;32(5):747-759. doi:10.1111/jpim.12176 
36. Trainor A, Trainer A, Graue E, editors. Reviewing Qualitative Research in the Social Sciences. Routledge, Taylor \& Francis Group. New York; 2013.

37. Morse J. Critical analysis of strategies for determining rigor in qualitative inquiry. Qual Health Res. 2015;25(9):1212-1222. doi:10.1177/1049732315588501
38. Mazor KM, Clauser BE, Field T, Yood RA, Gurwitz JH. A demonstration of the impact of response bias on the results of patient satisfaction surveys. Health Serv Res. 2002;37(5):1403-1417. doi:10.1111/1475-6773.11194 


\section{Supplementary materials}

1. Semi-Structured Interview (Practitioners, 2-4 weeks Post-Assessment)

Thank you so much for agreeing to participate in our study. We will be recording our conversation if that is okay with you. The purpose of this interview is to examine the experiences of Physical Therapists and Nurse Practitioners using videoconferencing to assess clients with chronic back pain. The objective is to determine perceptions of Nurse Practitioners and Physical Therapists following utilization of videoconferencing for interprofessional assessment and management of people with chronic back pain.

I want to remind you that your participation is voluntary. You can take a break if you need one. Do you have any questions before we begin?

a. How confident were you using videoconferencing for healthcare delivery to patients with chronic back pain? Why or why not?

1. Not confident at all

2. A little confident

3. Neutral

4. Moderately confident

5. Extremely confident

b. How confident were you with your role in an interprofessional team delivering healthcare to patients with back pain? Why or why not?

c. Did you feel like you were able to address all of your client's needs regarding their back pain using this method of care? Why or why not?

d. With ongoing availability of videoconferencing and a Physical Therapist/Nurse Practitioner colleague for this purpose, would your role change due to the new method of care?

e. Are you doing anything now that you did NOT do prior to this new method of care?

f. Could you communicate well throughout the assessment with the patient and other health care practitioner? Why or why not?

g. Were there any other challenges of this method of care and could please give examples?

h. What were the strengths of this method of care and could you please give examples?

i. What do you think are the observed or expected impacts of using videoconferencing for this type of care on people with chronic back pain? j. What do you think are the observed or expected impacts of using interprofessional teamwork for this type of care on people with chronic back pain?

k. How could other members of the health care team be integrated into this method of care? Which team members? What would be the strengths or challenges of adding team members?

1. Would you use videoconferencing again or recommend it to a colleague for a similar clinical situation? Why or why not?

$\mathrm{m}$. Is there anything else you want to tell us that we have not covered today?

2. Semi - Structured Interview (Participants, 2-4 weeks Post Assessment)

Thinking back to your assessment appointment, can you tell me about your experience of having your back problem assessed by a Nurse Practitioner and Physical Therapist through videoconferencing?

a. How comfortable were you with the Nurse Practitioner using videoconferencing for your back assessment? Why or why not?

b. Could you communicate adequately throughout the assessment with both the Nurse Practitioner and the Physical Therapist? Why or why not?

c. Were there any challenges with the assessment due to the videoconferencing format? Why or why not?

d. Could you see any challenges with using videoconferencing for this type of ongoing health care? What were they?

e. Could you see any benefits to you in using videoconferencing for this type of assessment? What would they be?

f. Would you attend a health care appointment in the future if you knew that videoconferencing was being used? Why or why not? Would you recommend it to a friend? Why or why not?

Now I'd like to ask you about your experience of being assessed by a team of health care providers ...

a. Have you had any previous experience being assessed by a team of two (or more) health care providers working together? If yes, please describe the past experience:

b. Please tell us what you thought about having both a nurse practitioner and a physical therapist see you at the same time for your back problem.

c. Did you feel your concerns about your back problem were being addressed? If yes, how so? If not, why not? 
d. What other types of health care providers have you seen in the past regarding your back problem (for example, Physical Therapist, Chiropractor, Massage Therapist, Family Doctor, Specialist et cetera)? How did this experience compare to any health care visits you have had in the past for your back problem (for example, by a Nurse Practitioner, Family Doctor or Physical Therapist)?

e. Is there anything else you would like to share with us about your experience with using a team to assess your back problem using videoconferencing?

\section{Publish your work in this journal}

The Journal of Multidisciplinary Healthcare is an international, peerreviewed open-access journal that aims to represent and publish research in healthcare areas delivered by practitioners of different disciplines. This includes studies and reviews conducted by multidisciplinary teams as well as research which evaluates the results or conduct of such teams or healthcare processes in general. The journal covers a very wide range of areas and welcomes submissions from practitioners at all levels, from all over the world. The manuscript management system is completely online and includes a very quick and fair peer-review system. Visit http://www.dovepress.com/testimonials. php to read real quotes from published authors. 